\title{
CONTRIBUIÇÃO AO ESTUDO DA DUREZA DOS GRÂNULOS ORIUNDOS DA GRANULAÇÃO DO GESSO AGRÍCOLA
}

\author{
L. M. RODRIGUES ${ }^{1}$, F. N. C. RODRIGUES ${ }^{1}$, M. M. SHIMANO ${ }^{1}$, A. F. DE LIMA², \\ R. F. PIRES ${ }^{1 *}$ \\ ${ }^{1}$ Universidade Federal do Triângulo Mineiro, Departamento de Engenharia Química \\ ${ }^{2}$ Universidade de Uberaba, Departamento de Engenharia Química \\ e-mail: ricardo@icte.uftm.edu.br
}

\begin{abstract}
RESUMO
A granulação é uma operação unitária que consiste em transformar pós finos em produto acabado com maior granulometria e dureza conferida aos grânulos. O presente trabalho visa à granulação do fosfogesso, o qual é um subproduto da obtenção de ácido fosfórico. A taxa de produção de fosfogesso é em torno de $4,5 \mathrm{~kg}$ por quilograma de $\mathrm{P}_{2} \mathrm{O}_{5}$ fabricado. Tal fato implica em problemas ambientais, como contaminação atmosférica por fluoretos, degradação de mananciais de água, solo e subsolo. Uma solução para o problema é a granulação do fosfogesso. Isto pode levar a uma melhor estocagem do produto que pode ser utilizado como fertilizante. Este projeto de pesquisa teve como objetivo estudar e determinar possíveis compostos a serem empregados em soluções como ligantes no processo de granulação do fosfogesso. Para isso foram usados três ligantes: Fécula de mandioca, Carboximetilcelulose e álcool polivinílico, em três concentrações diferentes. Os testes foram realizados em um granulador de disco rotatório. Para o tratamento dos dados foi feito um teste de comparação entre os tratamentos, a fim de avaliar se há diferença entre as concentrações. Os resultados obtidos mostram que analisando apenas a porcentagem granulométrica, o ligante que obteve maior rendimento foi o CMC, e a melhor concentração foi a maior para todos os ligantes. Quanto à resistência a fécula obteve valor mais satisfatório e através da análise estatística foi possível observar que a concentração influencia no processo.
\end{abstract}

\section{INTRODUÇÃO}

A granulação é uma operação unitária, em que os pós finos são transformados em grânulos para melhorar a aparência, as propriedades de escoamento e uniformidade de mistura, reduzir a formação de poeira e produzir partículas modificadas com propriedades melhoradas. $\mathrm{O}$ processo de granulação de fertilizantes é influenciado por muitas variáveis responsáveis pela obtenção pela geração de um produto final de boa qualidade. Entre essas variáveis estão: umidade, velocidade de rotação do granulador, tempo de granulação, distribuição de tamanho das partículas alimentadas, entre outras (ARAÚJO, 2010).

Quanto à umidade, a razão adequada entre a fase líquida e os sólidos é um fator que determina o sucesso da granulação, esta razão deve ser determinada em ensaios preliminares e está diretamente ligada ao tipo de granulador e à formulação do fertilizante (WALKER, 2007).

A velocidade de rotação do disco é um dos parâmetros que podem ser facilmente 
manipulados a fim de tentar aperfeiçoar o processo de granulação. A velocidade ótima de rotação é equivalente à metade da velocidade crítica que é a menor velocidade em que o material seco pode ser carregado ao redor do disco, sem que haja queda através da força centrifuga (WALKER, 2007).

O tamanho inicial das partículas alimentadas ao granulador é de extrema importância para uma granulação de sucesso. A uniformidade da massa inicial influencia diretamente o processo de granulação. Sendo que, uma distribuição irregular dificultará a homogeneidade da operação (GONÇALVES, 2011).

Existem dois métodos de granulação: por via seca e por via úmida. Na granulação por via úmida convencional, a fase líquida, geralmente água ou outros solventes orgânicos voláteis, isolados ou contendo substâncias aglutinantes são adicionados à mistura de pós, devendo promover dissolução apenas parcial dessa mistura. A substância aglutinante pode ser adicionada à mistura de pós à seco ou dispersa em um solvente (COUTO et al, 2000).

$\mathrm{O}$ gesso agrícola, sulfato de cálcio $\left(\mathrm{CaSO}_{4} \cdot \mathrm{nH}_{2} \mathrm{O}\right)$ é subproduto da fabricação do ácido fosfórico, que é necessário à produção de superfosfato triplo e fosfatos de amônio. Devido à grande quantidade com que é obtido, isto é, para cada tonelada de $\mathrm{P}_{2} \mathrm{O}_{5}$ produzida na forma de ácido fosfórico, obtém-se 4,5 toneladas de gesso, seu acúmulo torna-se um transtorno para a indústria (LOPEZ et al, 2010).

Dentre todas as possíveis aplicações do gesso agrícola, destaca-se o uso para melhora e condicionamento de solos, fornecimento de cálcio e enxofre bem como a diminuição dos teores de alumínio tóxico, possibilitando um maior crescimento radicular. Para solucionar problemas com manuseio e minimizar perdas na aplicação é que se opta por granular o gesso. Outra questão é o fato de representar uma solução sustentável, pois também preserva o bem estar do agricultor (que não vai aspirar o fino pó) que manipula o produto gesso mineral ou agrícola na forma sólida granular (LOPEZ et al, 2010).

Esta pesquisa teve como objetivo geral estudar/determinar possíveis compostos a serem empregados em soluções como ligantes no processo de granulação do gesso agrícola. Além disso, estudar o efeito da adição de cada tipo de composto na solução ligante, bem como a influência da concentração de cada composto (PVA, CMC, fécula de mandioca) da solução ligante a ser empregada no processo de granulação do gesso agrícola.

\section{METODOLOGIA}

Neste trabalho, a unidade piloto a ser utilizada para granulação do gesso agrícola é um granulador de disco rotatório, constituído de um prato granulador com $60 \mathrm{~cm}$ de diâmetro, conectado a um eixo que por sua vez gira por meio de um motor. No equipamento descrito pode-se controlar o ângulo de inclinação do prato/disco, a velocidade e o sentido de rotação. Com o auxílio de testes preliminares foram fixadas inclinação, velocidade, e sentido do disco, a fim de se avaliar apenas as características dos ligantes. A inclinação utilizada foi $45^{\circ}$ e a velocidade $26 \mathrm{rpm}$, rotacionando no sentido anti-horário.

Os ligantes utilizados, bem como as três concentrações testadas se encontram listados na Tabela 1. 
Tabela 1 - Relações de massa utilizadas para os testes

\begin{tabular}{cc}
\hline Ligante & $\begin{array}{c}\text { Relação } \\
\text { [g ligante } / \mathrm{g} \text { fosfogesso] }\end{array}$ \\
\hline \multirow{3}{*}{ Fécula } & $25,6 \mathrm{~g} / 250 \mathrm{~g}$ de fosfogesso \\
& $32,0 \mathrm{~g} / 250 \mathrm{~g}$ de fosfogesso \\
& $38,4 \mathrm{~g} / 250 \mathrm{~g}$ de fosfogesso \\
\hline \multirow{3}{*}{ CMC } & $3,00 \mathrm{~g} / 250 \mathrm{~g}$ de fosfogesso \\
& $6,25 \mathrm{~g} / 250 \mathrm{~g}$ de fosfogesso \\
& $9,50 \mathrm{~g} / 250 \mathrm{~g}$ de fosfogesso \\
\hline \multirow{3}{*}{ PVA } & $3,00 \mathrm{~g} / 250 \mathrm{~g}$ de fosfogesso \\
& $6,25 \mathrm{~g} / 250 \mathrm{~g}$ de fosfogesso \\
& $9,50 \mathrm{~g} / 250 \mathrm{~g}$ de fosfogesso \\
\hline
\end{tabular}

No procedimento experimental, soluções de concentrações conhecidas dos ligantes a serem testados foram convenientemente preparadas de acordo com a Tabela 1 .

Para uma melhor granulação o gesso foi seco e separado a uma granulometria de $600 \mu \mathrm{m}$. Além da separação do ligante e do fosfogesso, são necessários também a utilização de uma solução de $\mathrm{NaOH}$ que foi aspergida no processo. A quantidade de $\mathrm{NaOH}$ e água foi fixada sendo $1,07 \mathrm{~g}$ de $\mathrm{NaOH}$ e $200 \mathrm{ml}$ de água.

O processo de granulação, portanto, se dá com a padronização da velocidade e a inclinação, para então ser feita a inserção do fosfogesso previamente misturado ao ligante em questão no disco. Depois de ligado o equipamento, foi iniciada a aspersão da solução de $\mathrm{NaOH}$. O processo de granulação durou em média 15 minutos. Após o tempo decorrido, todo material era colocado em um recipiente e levado para a estufa à $70^{\circ} \mathrm{C}$, a fim de retirar toda a umidade restante.

Depois da realização do processo de granulação as amostras já secas foram levadas para a análise granulométrica. Para tanto utilizou-se peneiras que compreendiam os diâmetros de partículas entre de 2 e $5,6 \mathrm{~mm}$. Também foram realizados testes de dureza com as amostras que obtiveram granulometria entre 2 e $5,6 \mathrm{~mm}$.
A Figura 1 mostra o equipamento utilizado no processo de granulação.

Figura 1: Granulador de disco Rotatório em escala Piloto.

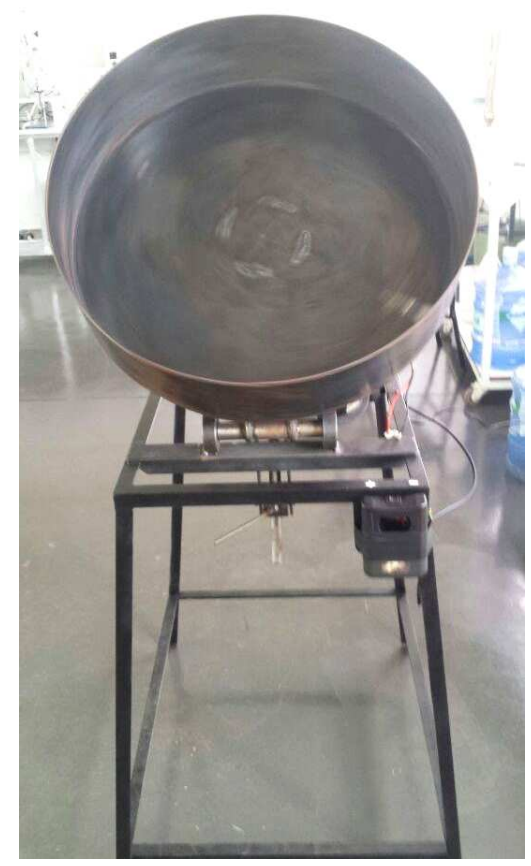

Para a realização do teste de dureza foi utilizada a máquina universal de ensaios mecânicos. Foi feito um acessório que acoplado à máquina conferiu sensibilidade para a célula de carga medir a máxima força de ruptura dos grãos. A velocidade utilizada nos ensaios foi de $1 \mathrm{~mm} / \mathrm{min}$.

\section{RESULTADOS E DISCUSSÃO}

Os dados analisados foram apenas os obtidos entre as faixas granulométrica 2 e 5,6 $\mathrm{mm}$, em que foi feita a média entre todas as amostras. As respostas obtidas através do processo de granulação foram: Porcentagem granulométrica e Resistência a força de compressão, ou seja, a dureza do grânulo. A Tabela 2 mostra os valores médios encontrados para cada resposta em função das concentrações de cada ligante. 
Tabela 2: Resultados obtidos para \% granulométrica e Dureza.

\begin{tabular}{cccc}
$\begin{array}{c}\text { Relação } \\
\text { (ligante [g]/ } \\
\text { fosfogesso [g]) }\end{array}$ & Ligantes & $\begin{array}{c}\% \\
\text { Granulométrica }\end{array}$ & $\begin{array}{c}\text { Dureza } \\
(\mathrm{N})\end{array}$ \\
\hline 0,1024 & & 68,23819 & 12,96 \\
0,1280 & Fécula & 63,13206 & - \\
0,1536 & & 81,70426 & 9,074 \\
\hline 0,0120 & & 82,50309 & 4,971 \\
0,0250 & CMC & 84,42122 & 2,186 \\
0,0380 & & 88,40889 & 1,456 \\
\hline 0,0120 & & 77,36050 & 3,829 \\
0,0250 & PVA & 78,98779 & 5,036 \\
0,0380 & & 81,23549 & 4,310 \\
\hline
\end{tabular}

É de extrema importância salientar que para a obtenção da granulometria os testes foram realizados em duplicata. Para a obtenção da dureza, foram realizados 20 testes para cada concentração.

$\mathrm{Na}$ Figura 3 está representado um gráfico que mostra a porcentagem granulométrica em relação a todos os ligantes propostos, levando em conta as diferentes concentrações estipuladas, incluindo apenas a faixa granulométrica entre 2 e 5,6 mm.

Figura 2: Porcentagem granulométrica a partir de cada ligante.

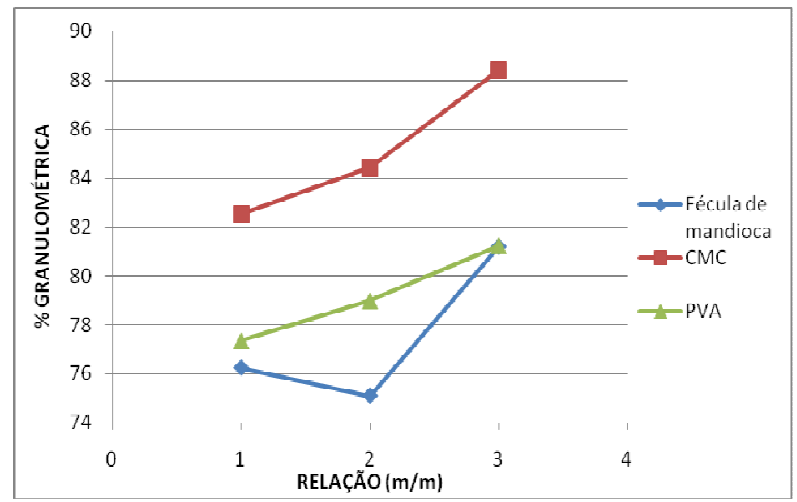

Deve-se observar na Figura 3 que no eixo das ordenadas, os valores 1, 23 correspondem respectivamente à menor, intermediária e maior concentração.
A partir da Figura 3 pode-se observar que o ligante que obteve melhor granulometria foi o Carboximetilcelulose, levando em conta as três concentrações estipuladas. E como o esperado, observando os três ligantes, a maior concentração resultou na maior porcentagem granulométrica. A fécula de mandioca, no entanto, foi a que mostrou maior não uniformidade quanto à granulometria.

Como foram realizados os testes apenas em duplicatas, não foi possível analisar estatisticamente, pois seriam necessários mais dados para que houvesse uma confiança nos resultados obtidos.

Alguns fatores podem ter influenciado a análise do processo de granulação. Como a aspersão é realizada manualmente, com o auxilio de um borrifador, se torna muito complicada a padronização dessa variável, outro problema decorre do fato de que o processo é realizado em local aberto, sujeito a interferências climáticas, como umidade do ar e ventos, que também prejudicam o andamento do processo.

Para auxiliar no cascateamento do pó a ser granulado, foi utilizada uma espátula, com a finalidade de simular um raspador. A raspagem também foi realizada manualmente, o que pode influenciar de alguma maneira o processo final.

Para eliminar algumas fontes de erros sistemáticos no modo de operação, o ideal seria a instalação de um raspador e um aspersor fixo, para que o processo se tornasse inteiramente mecânico.

A fim de analisar a resistência dos grânulos com faixa entre 2 e $5,6 \mathrm{~mm}$, ensaios mecânicos foram realizados com 20 amostras. Devido ao número de amostras, é possível analisar estatisticamente os dados de resistência. Como as concentrações analisadas para cada ligante foram diferentes, não é possível fazer uma análise fatorial entre os ligantes. 
Os valores médios obtidos para a resistência, bem como o desvio padrão estão expressos na Tabela 3 .

Tabela 3: Valores médios e desvio padrão da resistência dos grânulos

\begin{tabular}{ccc}
\hline Ligante & $\begin{array}{c}\text { Resistência } \\
\text { Média }(\mathrm{N})\end{array}$ & $\begin{array}{c}\text { Desvio } \\
\text { Padrão }\end{array}$ \\
\hline \multirow{3}{*}{ PVA } & 3,8294 & 1,2430 \\
& 5,0306 & 0,9168 \\
& 4,3100 & 0,8205 \\
\hline \multirow{3}{*}{ Fécula } & 12,960 & 3,6764 \\
& - & - \\
\hline \multirow{2}{*}{ CMC } & 9,0740 & 1,5334 \\
& 4,9717 & 2,9422 \\
& 2,1866 & 0,9419 \\
& 1,4565 & 0,6044 \\
\hline
\end{tabular}

A análise estatística utilizada foi uma comparação entre os tratamentos em que foram analisadas duas hipóteses, $\mathrm{H}_{0}$ e $\mathrm{H}_{1}$, onde $\mathrm{H}_{0}$ é a hipótese onde as amostras $\mathrm{n}_{1}$ e $\mathrm{n}_{2}$ são iguais e $\mathrm{H}_{1}$ é a hipótese onde as amostras $\mathrm{n}_{1}$ e $\mathrm{n}_{2}$ são diferentes. Quando as amostras forem iguais significa que não há influência da variável analisada na resposta. Caso as amostras sejam diferentes conclui-se que a variável influencia na resposta encontrada. As Equações 1 e 2 demonstram o funcionamento do teste de hipótese.

$H_{0}: n_{1}-n_{2}=0$ (as amostras são iguais)

$H_{1}: n_{1}-n_{2} \neq 0$ (as amostras são diferentes)

Para este trabalho foi utilizado um intervalo de confiança de $90 \%$, ou seja, a é igual a 0,1 , e como o teste é bicaudal $\alpha / 2$ é igual a 0,05 .

Isso quer dizer que se o valor de $\mathrm{p}$ analisado entre os tratamentos for menor que 0,05, estará na região de rejeição, ou seja, rejeita a hipótese $\mathrm{H}_{0}$, portanto as amostras são diferentes.
A Tabela 4 mostra a comparação entre os tratamentos para cada ligante, bem como o valor de p obtido.

Tabela 4: Valores obtidos de $\mathrm{p}$.

\begin{tabular}{ccc}
\hline Ligantes & Comparação entre tratamentos & $\mathrm{p}$ \\
\hline \multirow{3}{*}{ PVA } & $0,012-0,025$ & 0,0037 \\
& $0,025-0,038$ & 0,0321 \\
& $0,012-0,038$ & - \\
\hline \multirow{3}{*}{ Fécula } & $0,1024-0,128$ & - \\
& $0,128-0,1536$ & - \\
\hline \multirow{3}{*}{ CMC } & $0,1024-0,1536$ & 0,0030 \\
& $0,012-0,025$ & 0,0011 \\
& $0,025-0,038$ & 0,0121 \\
& $0,012-0,038$ & 0,0001 \\
\hline
\end{tabular}

Vale salientar que as interações com a concentração intermediária de fécula não puderam ser realizadas já que os grânulos se mostraram muito porosos, diferentemente das outras amostras, então se optou por não avalia-los já que provavelmente o teste teria como resultado a uma dureza irreal.

Analisando os valores encontrados na Tabela 4, em relação ao PVA as amostras analisadas se mostraram diferentes já que as estimações encontradas para $p$ foram abaixo de 0,05 , isso mostra que na análise realizada para a obtenção da resistência dos grânulos, a concentração influencia, a mesma análise é obtida para o CMC e a fécula.

Para a fécula de mandioca, não é possível concluir com certeza se não há nenhuma amostra que seja igual, já que nem todas as comparações entre os tratamentos foram possíveis de serem realizadas.

Para o CMC, fica bem claro ao observar os valores de p que as amostras são diferentes, donde pode-se afirmar que a concentração influencia diretamente na dureza.

É de extrema importância dizer que os valores obtidos para a dureza são valores baixos, isso se deve pela concentração que foi estipulada. Como não há dados na literatura para a granulação utilizando estes ligantes, as 
concentrações foram estipuladas a fim de se conhecer como era o comportamento dos ligantes nas condições fornecidas.

Observando os valores de dureza o ligante que obteve maior valor desta grandeza foi a fécula de mandioca, já o CMC e o PVA alcançaram valores bem menores. Isso deve ao fato de que a concentração utilizada para a fécula foi maior que a concentração empregada nos testes com o CMC e PVA.

\section{CONCLUSÃO}

Diante dos resultados obtidos da Tabela 1, conclui-se que os ligantes CMC e PVA possuem um rendimento maior que a fécula de mandioca, em torno de 15 pontos percentuais para concentrações mais baixas. Já para concentrações mais altas, os rendimentos entre os três ligantes são de aproximadamente $80 \%$.

Por outro lado, com os resultados obtidos da Tabela 3, em termos de resistência a força de compressão, a fécula de mandioca apresentou melhores resultados perante $\mathrm{o}$ PVA e à CMC. A força média para os grãos que foram utilizados fécula de mandioca é próximo de $1 \mathrm{kgf}$ (aproximadamente 10 Newton).

Utilizando a Tabela 3, nota-se que o desvio padrão é menor para a CMC, ou seja, os grãos são uniformemente distribuídos quanto a dureza.

Ainda em relação à granulometria, pode-se concluir que houve um aumento diretamente proporcional em relação à concentração e granulometria, esse aumento é observado em todos os ligantes. Sendo que, com a maior concentração obteve-se a maior porcentagem granulométrica alcançada.

Apesar de a granulação ser uma operação unitária corriqueiramente empregada na indústria, é muito difícil repetir com a mesma fidelidade todos os testes. Há dificuldades tais como variações na umidade do ar, velocidade do ar, posição do cascateamento, a distribuição dos ligantes no gesso, a posição da aspersão e outras variáveis relacionados ao fator humano e operacional do equipamento.

\section{REFERÊNCIAS}

ARAÚJO, Michele Morais. Relatório Técnico Complexo de Piaçaguera. Piaçaguera: Vale Fertilizantes, 2010.

COUTO, A. G.; ORTEGA, G. G.; PETROVICK, P. R. Granulação. Programa de Pós-graduação em Ciências Farmacêuticas, Faculdade de Farmácia, 2000.

GONÇALVEZ, C. R. Granulação de Fertilizantes: Influência de Variáveis de Processos na Granulometria dos Grânulos. 2011. Trabalho de conclusão de curso, Faculdade de Engenharia Química, Universidade Federal de Uberlândia, Uberlândia, 2011.

LÓPEZ R. P., NIETO J. M., COTO I. L., AGUADO J. L., BOLÍlVAR J. P., M., Dynamics of contaminants in phosphogypsum of the fertilizer industry of Huelva (SW Spain): from phosphate rock ore to the environment, 2010.

WALKER G. M. Handbook of Powder Technology: Granulation (Chapter 4 Drum Granulation Processes), Northern Ireland (UK), outubro 2007.

\section{AGRADECIMENTOS}

Os autores agradecem a colaboração da instituição UFTM (Universidade Federal do Triângulo Mineiro) e a empresa Labfert de Uberaba. 